\title{
Fatigue of the automobile structural materials in corrosive environment
}

\author{
German Pachurin ${ }^{1}$, Diana Goncharova ${ }^{1}$, Gor Gevorgyan ${ }^{1}$, Aleksey Filippov ${ }^{1}$, Marya \\ Mukhina $^{2 *}$, Irina Trunova $^{1}$, and Natalia Koniukhova ${ }^{1}$ \\ ${ }^{1}$ Nizhny Novgorod State Technical University named after R.A. Alekseev, Minin Street, 24, Nizhny \\ Novgorod, 603950, Russia \\ ${ }^{2}$ Minin Nizhny Novgorod State Pedagogical University, Chelyuskintsev street, 9, Nizhny Novgorod, \\ 603138, Russia
}

\begin{abstract}
Operation of machines and equipment is accompanied by an impact produced by various types of loads leading to fatigue rupture of the structural materials. The most harmful are the vibration loads which in a corrosive environment increase the potential for a failure resulting in human casualties. Therefore, the task of ensuring the operating capability of machine elements and assemblies is one of the outstanding tasks for all industry sectors. In addition, the need for extending the service life and increasing the operational reliability is also determined by a relatively high cost of the machine structural materials and hardware items. Therefore, the execution of the experimental studies of the structural material fatigue features with a view to reduce the metal consumption, to establish new processing methods as well as to select a competitive material, are of the priority for the up-to-date machine building sector. The purpose of this article is to determine any fatigue behavior regularities in automotive materials which were pre-processed according to various technology types and modes and which were operating in a corrosive environment. The experimental data analysis has demonstrated that the longer the cyclic metal materials testing is run, the more sufficient is the decrease of the fatigue resistance of these.
\end{abstract}

\section{Introduction}

When in operation, machines and equipment are subject to various types of loads leading to the structural material fatigue rupture. The most harmful are the vibration loads which in a corrosive environment increase the potential for emergencies $[1,2]$. Therefore, the task of ensuring the operating capability of machine elements and assemblies is one of the outstanding tasks for all industry sectors.

Operating performance of the structural materials intended for manufacturing of the machine building hardware items is formed at all stages of metallurgical treatment: from selection of furnace charge used for metal smelting to the final item production [3-5]. Another reason to increase the service life and operating reliability is the high cost of the

\footnotetext{
* Corresponding author: mariyamuhina@yandex.ru
} 
automotive structural materials. Therefore, the experimental studies of the structural material fatigue features with a view to reduce the metal consumption, to establish new processing methods as well as to select a competitive material, are of the priority for the upto-date machine building sector.

This issue solution provides for the study of the structural metal and alloy fatigue rupture in conditions of any corrosive environment presence and with a capability to determine the duration of the period preceding the cracks origination and to determine further the structural body crack propagation rates. This will help to select a material meeting the operating requirements and, as a consequence, to prevent its fatigue rupture, to ensure reduction of financial and time-consumption costs associated with a motor car repair [6].

The machine and mechanical device elements are manufactured based on various technologies [7-9]. However, the study of the material fatigue rupture during the process of the fatigue life is associated with a considerable test duration and test conditions [10]. Therefore, to determine the behavior regularities in the case of the automotive materials pre-treated according to various technology types and modes is relevant. In this case, apart from the hardware item manufacturing technology development, one shall consider all the factors affecting the operating endurance.

\section{Analytical review}

The structural materials fatigue resistance in a corrosive medium considerably fades as a rule $[11,12]$, therefore the fatigue curves in the multi-cycle area continuously decline not reaching [1] the endurance limit.

A zero-to-tension net curve $(167 ; 16.7$ and $1.67 \mathrm{MHz})$ of the smooth 15HN5DMF steel sample has shown [13] that the sea water to a lesser extent affects the duration before any crack appearance but reduces the phase of its propagation. In this case the comparison of short and long cracks development kinetics in steel grades A53CL1 (makeup in \%: C 0.13; Mn 1.48; P 0.012; S 0.005; Si 0.46; Mo 0.016; Cr 0.04; N 0.18; Cu 0.17 and V 0.051) [7] and St JIS SNCM439 (in \%: C 0.42; Si 0.24; Mn 0.9; P 0.019; S 0.008; Ni 1.77; Cr 0.78; Mo 0.1) [14] demonstrated a considerable $(\approx 10$ times) acceleration of the short crack propagation as compared to the long ones. The short cracks have an intergranular character whereas the long ones pass through the entire crystal grain.

The load frequency reduction leads to a durability reduction when placed inside the environment: with steel grades 15HN5DMF [13] (in the area of 167 to $1.67 \mathrm{MHz}$ ), 422 , SVS410 (in \%: C 0.25; Ni 0.77; Cr 12.39; Mo 1.12; V 0.28; W 1.08), SVS410 (in \%: C 0.09; Si 0.38; Mn 0.33; P 0.021; S 0.008; Cr 13.08) [15] (in the range of 10 to $0.1 \mathrm{~Hz}$ ), low alloy Cr-Mo-steel [15] (at frequencies of 30 to $0.03 \mathrm{~Hz}$ ), high-strength steel AISI 4340, $12 \mathrm{Ni}-5 \mathrm{Cr}-3 \mathrm{Mo}, 10 \mathrm{Ni}-\mathrm{Cr}-\mathrm{Mo}-\mathrm{Co}$ and maraging steel with $18 \%$ of $\mathrm{Ni}$ [16], 200 (makeup: $18 \mathrm{Ni}-3.2 \mathrm{Mo}-0.2 \mathrm{Ti}-0.1 \mathrm{AC}-8.5 \mathrm{Co}-0.035 \mathrm{C}$ ) [17] (in the interval between 3.3 and $0.017 \mathrm{~Hz}$ ), $33 \mathrm{NiCr}$ (in \%: C 0.37; Ni 3.5; Cr 1.35; Mo 0.25; V 0.1; Si 0.3; Mn 0.4) [18] (in the range of 36 to $0.3 \mathrm{~Hz}$ ), alloys (makeup in \%): nimonic-105 (C 0.2; Cr 14.5; Co 20; Mo 5; Al 1.8; Ti 4.5) and IN738C (C 0.17; Cr 16; Co 8.5; Mo 1.7; W 2.6; Ta 1.7; Nb 0.9; Al 3.4; Ti 3.4; Zr 0.1 ) [19] (at frequencies of $10^{2}$ to $10^{-4} \mathrm{~Hz}$ ).

However there are other data indicating at the fact that the load frequency effect on the corrosion fatigue resistance of the steel grades is of a non-monotonous character, for example, En56C (in \%: C 0.24; Si 0.34; Mn 0.27; Cr 13.38; Ni 0.41; S 0.011; P 0.019) and A533B-1 (in \%: C 0.18; Si 0.26; Mn 1.50; Ni 0.59; S 0.009; P 0.010) [20] when changing frequency from 0.001 to $10 \mathrm{~Hz}$, in austenitic steel grades $316 \mathrm{~L}$ (in \%: C 0.03; Cr 17.8; Ni 14.1; Mo 2.5; Si 0.44) and 316S16 (in \%: C 0.02; Cr 18.2; Ni 12.7; Mo 2.1; Mn 1.03; Si $0.59)$ [21]. 
In some cases, there is [22] a limit frequency below which the corrosion fatigue crack development rate in steel grades of type $12 \mathrm{H} 2 \mathrm{~N}$ either slightly increases or decreases.

The loading cycle pattern insignificantly influences the metal materials fatigue in operating environments at low stresses [23], however at high stresses this influence increases. In this case the sample durability when tested according to a sinusoidal pattern is lower than that under the rectangular or trapezoidal pattern. Thus, the study of the smooth samples with the flat cross section made of steel 15HN5DMF for the zero-to-tension net curve has shown that [13] the origination and propagation of a fatigue crack under a sinusoidal cycle in sea water occur more actively by $10-90 \%$ than that under the trapezoidal pattern. In this case the cycle pattern effect increases with the growth of the fatigue rupture level.

The lower is the stress intensity in the crack tip, the more sufficiently the growth of the cycle asymmetry determines the reduction of the material corrosion fatigue resistance. The cycle asymmetry increase also provokes a decrease in the stress intensity threshold factor $K_{t h}[24]$ and the difference between the crack development in sea water and in air [25]. In the case of the sea vessel hull plate steel grade 10HSND for the net curve with frequency 35 $\mathrm{Hz}$ in natural sea water, an increase of the load cycle asymmetry factor does not influence the crack origination and propagation but leads to a reduction of the cracks amount. In steel grade BS 817M40 of improved purity (in \%: P 0.16; S 0.030; As 0.032; Sn 0.019; Sb 0.065 ), fatigue tested [26] at $\mathrm{R}=0.1$ and $0.35,35 \%$ of the fatigue rupture is represented by the intergranular constituent while at $\mathrm{R}=0.7$ the share of this reaches $\sim 10 \%$ only.

Based on the data [1] the most important factor influencing the material environment fatigue resistance is the degree of the environment corrosive power. Often hydrogen charging of metals, especially that of the high-strength steel grades having a high sensitivity to hydrogen embrittlement, is determining for an alternating loading.

The study of a cyclic crack resistance of stainless steel grades $08 \mathrm{H} 17 \mathrm{~T}$ and $12 \mathrm{H} 18 \mathrm{~N} 10 \mathrm{~T}$ at zero-to-tension cycle with frequency of $2.5 \mathrm{~Hz}$ demonstrates [27] that in the hydrogen charged (aqueous solution of sulfuric acid with addition of $5 \mathrm{ml} / 1$ of arsenic dioxide) and pre-hydrogen charged environment, the crack development rate is by an order of magnitude greater than that in the air. Hydrogen charging at fatigue rupture causes a controlling effect on the crack development rate which is associated with a sharp reduction of the metal surface plasticity due to hydrogen adsorption or to embrittling effect of the surface oxidation and hydrogen release reactions.

Using the samples made of Inconel-718 heat-resistant alloy, molybdenum doped steel $\mathrm{X} 20 \mathrm{CrMo} 13$ and titanium VT1-0, it was shown that the hardware item service life extension in the event of the environment-related fatigue may be achieved implementing materials with a high $K_{t h}$ (stress intensity threshold factor) or by execution of activities aimed at increasing this [28]. This reduces potential occurrence of any deeper cracks developed due to a fatigue fretting.

The study of aluminum alloy ACpl [29] has brought to life equal slip and crack formation both in air and in 3\% solution of sea salt in water although in water and especially in $3 \%$ solution of $\mathrm{NaCI}$ these accelerate considerably.

Joint effect of environment and alternating loading due to the passive film destruction [29] and barrier elimination, preventing the dislocations to get onto the metal surface, accelerates micro and sub-micro-deformations in the metal and passivation on the contrary retards the dislocation outlet slowing down the corrosion fatigue damage kinetics acceleration.

Due to the adsorption or adsorption-electrochemical effect produced by the environment the initial phase of the corrosion fatigue as in the case of corrosion cracking, is determined by the local damage of the material surface passive layer. However, if in the first case initially the trans-granular slip intensity increases and only after it in the slip band there 
appear juvenile metal planes, in the second case the fresh surfaces are immediately formed in the dislocation accumulations.

Previously we have demonstrated, based on direct microscopic survey of the operating surface of the sample critical section [1] that the fatigue rupture in presence of an environment starts in spot corrosion damages originated predominantly near the non-metal inclusions at steady slip bands where the metal volume is the most activated and serves as an anode for adjacent surfaces. Further these damages are deepened, due to localization of stresses and intensity of electrochemical processes the metal thermodynamic activity increases. The pitting plugging with secondary corrosion products slowing down the oxidation process during alternating loading becomes more difficult.

Therefore, in the case of the samples without the cracks preliminary applied, many corrosion fatigue micro-cracks develop on the surface located close to each other and jointly affecting the mechanical stress distribution fields. In this case the cracks are not right-lined and are considerably ramified. Thus, according to the available literature all this makes it problematic to determine the moment of the macro-crack origination in order to make an analytical estimate of the time before its origination.

The fatigue crack development stages $[1,23]$ are described by the fatigue rupture (FRKD) kinetic diagram which is a curve of the crack development rate change with the increase in the amplitude of the (SIF) stress intensity factor.

The complete diagram has a complex appearance, therefore multiple attempts to describe it using a uniform analytical dependency failed to be entirely successful (Forman, Kerny, Erdogan, G.P. Cherepanov, V.D. Kuliyev, S.Ya. Yarema, S.I. Mikishin et al).

The corrosion fatigue rupture kinetic diagram configuration features for various structural materials are detailed in the article [30].

As distinct from the cracks developing without participation of corrosive environments, the corrosion fatigue ruptures have the peculiarities of their own [1], determining the character of the driving force and the kinetics of corrosion cracks propagation not described within the frameworks of traditional analysis of the rupture mechanics. A strained condition in the tip of a corrosion fatigue crack may be considerably reduced due to its ramification and blunting (corrosion attack), as well as due to the crack closure effect facilitating the stress relaxation, i.e., reduction of effective SIF, and the crack closure leads to reduction of the effective amplitude of SIF. All this influences the rupture process.

During the comparative tests when it is required, for example, to determine the effect of environment, stress concentrator, thermal and other treatment technology on the structural material fatigue resistance, one often uses relative values [2].

However, the advantages of such kinetic approach are manifested only in cases, when macro-cracks are already present in the metal, the plane of the crack development is perpendicular to the normal stress application direction and the stress intensity in its apex is controllable. In the case of the smooth samples without preliminary applied cracks as is shown above there is a great amount of corrosion fatigue micro-cracks emerge immediately on the surface, located close to each other and jointly influencing the distribution of the stress fields. Therefore, it is impossible to determine the value of the stress intensity in the tip of the developing crack based on the known methods. Also, very often the cracks have a ramified character and not the right-lined one. This, in turn, makes it difficult to apply the known rupture mechanics hypotheses to the corrosion fatigue kinetics analytical description.

\section{Experiment results}

It was experimentally discovered $[1,11]$ that the deflection curves are integral characteristics of the structural transformations in materials during the fatigue stress 
process. As an example, investigated in the work curve of deflection change in a corrosive environment is showed for a L63 brass sample during the cyclic load with the stress amplitude of $300 \mathrm{MPa}$.

This makes it possible to track the number of cycles till a crack originates and to track its development activity which is considerably relevant in those cases when any direct observation of structural change of the critical section surface is excluded, e.g. in a corrosive environment conditions.

Table 1 shows the comparison of the deflection curves processing results in the event of the sample fatigue taking place in air and in a corrosive environment.

Table 1. Comparison of the deflection curves processing results for L63 brass samples placed in air and a corrosive environment (stress amplitude $300 \mathrm{MPa}$ ).

\begin{tabular}{|c|c|c|c|c|}
\hline$N_{p}$, cycle & $N_{\text {3. } m p ., \text { cycle }}$ & $N_{p}-N_{3, m p}$, cycle & $l \mathrm{~s}, \mathrm{~mm}$ & $V_{m p .}, \mu \mathrm{m} /$ cycle \\
\hline 3 & 4 & 5 & 6 & 7 \\
\hline \multicolumn{5}{|l|}{ In air } \\
\hline 341000 & 270000 & 71000 & 3.66 & $5.15 \cdot 10^{-2}$ \\
\hline \multicolumn{5}{|c|}{ In a corrosive environment } \\
\hline 51000 & 40000 & 11000 & 3.10 & $48.2 \cdot 10^{-2}$ \\
\hline \multicolumn{5}{|c|}{$\begin{array}{l}\text { Note: } \\
N p-\text { complete endurance, cycle; } \\
N \text { 3. } m p .- \text { number of cycles prior to crack origination, cycle; } \\
N p-N 3 . m p-\text { number of run cycles with a crack, cycle; } \\
l s \text { - length of a purely fatigue crack at the sample's fracture point, } \mathrm{mm} ; \\
V m p . \text { - crack propagation rate, } \mu \mathrm{m} / \text { cycle. }\end{array}$} \\
\hline
\end{tabular}

\section{Conclusions}

Combined with metallographic and fractographic analysis methods the curves of deflection change during the cyclic load make it possible to execute optimization of material selection to be used for automotive parts manufacturing, increasing the parts service life and maintainability.

\section{References}

1. G.V. Pachurin, Corrosion fatigue life of articles from mechanically hardened metals and alloys: Training book. 2-nd edition, supplemented, 160 (Lan, 2014)

2. G.V. Pachurin, Fundamental research 3(1), 28-34 (2014)

3. G.A. Gevogian, R.A. Vorobyev, G.V. Pachurin, A.A. Filippov, M.V. Mukhina, L.I. Kutepova, Scopus International Scientific Electric Power Conference, IOP Conf. Series: Materials Science and Engineering 643, 012127 (2019). DOI:10.1088/1757899X/643/1/012127.

4. G.V. Pachurin, A.A. Filippov, T.V. Nuzhdina, U.I. Matveev, M.V. Mukhina, IOP Publishing, Journal of Physics: Conference Series 1353, 012087 (2019). DOI:10.1088/1742-6596/1353/1/012087.

5. G.V. Pachurin, A.A. Filippov, D.A. Goncharova, T.V. Nuzhdina, U.I. Matveev, M.V. Mukhina, L.I. Kutepova, IOP Conf. Series: Materials Science and Engineering 632, 012037 (2019) DOI:10.1088/1757-899X/632/1/012037.

6. G.V. Pachurin, A.A. Filippov, I.G. Trunova, G.A. Gevorgyan, M.V. Mukhina, Proceedings of the Seventh International Environmental Congress "Ecology and Life 
Protection of Industrial-Transport Complexes" ELPIT 2019, Edition ELPIT 201(9), 115-123 (2019)

7. P. Hongxun, Y. Jigjun, K. Wei, Tzin-shu-snebao, Acta met. Sin 24(6), B393-B397 (1988)

8. A.A. Filippov, G.V. Pachurin, D.A. Goncharova, T.V. Nuzhdina, M.V. Mukhina, O.V. Katkova, U.I. Matveev, T.N. Tsapina, IOP Conf. Series: Materials Science and Engineering, 632, 012010 (2019). DOI:10.1088/1757-899X/632/1/012010.

9. G.V. Pachurin, S.M. Shevchenko, A.A. Filippov, M.V. Mukhina, N.A. Kuzmin, IOP Conf. Series: Materials Science and Engineering 327, 032040 (2018). DOI: $10.1088 / 1757-899 \mathrm{X} / 327 / 3 / 032040$.

10. A.A. Filippov, G.V. Pachurin, N.A. Kuzmin, T.V. Nuzhdina, D.A. Goncharova., Metallurgical science and metals thermal treatment 8, 58-61 (2019)

11. G.V. Pachurin, Russian Engineering Research 32, 9-10, 661-664 (2012)

12. G.V. Pachurin, Technology of metals 10, 16-21 (2003)

13. G.G. Maksimovich, A.V. Kobzaruk, Physical chemistry of mechanical materials, 5(5), 16-20 (1984)

14. N. Yoshikazu, A. Hedenari, K. Yasuhiro, O. Kiyotsugu. Nippon kikay gakkay rombusu. Trans. Jap. Soc. Mech. Eng. A55(516), 1724-1731 (1989)

15. N. Satashi, A. Takayuki, M. Chitoshi, H. Hisashi, Nippon kikay gakkay rombusu. Trans. Jap. Soc. Mech. Eng. A51(461), 156-160 (1985)

16. N. Kin-ichi, Yesetsu gakkaisi, J.Jap. Weld. Soc. 55(11), 926-937 (1976)

17. R. Eisenstadt, D.L. Smail, Adv. Res. Strength Fract. Mater. 4th Int. Conf. Fract., 911918 (1977-1978)

18. E. Schmidtmann, D.A. Wirths, Arch Fisenhuttenw 49(10), 433-437 (1973)

19. D.E. Pettit, J.T. Ryder, W.E. Krupp, R.B. Hoeppner Scarlin, Adv. Res. Strength Fract. Mater. 4th Int. Conf. Fract., 849-857 (1977-1978)

20. L.D. Atkinson, T.S. Lindley, Influence Environment Fatigue Conf., 65-74 (1977)

21. E. Smethurst, R.B. Waterhouse, Proc. 2th Int. Conf. Mech. Behav. Mater., Boston, Mass., 1, 695-699 (1976)

22. A.N. Magdenko, V.I. Sadychenko. Physical chemistry of mechanical materials 5, 102103 (1984)

23. V.F. Terentiev, A.B. Petukhov, Fatigue of high-resistant steel materials, 515 (IMET RAS - TSIAM, Moscow, 2013)

24. C. Daolun, W. Zhongguang, J. Xioaxia, A. Suhua, Sh. Changxu, Steel Res. 59(7), 319322 (1989)

25. S. Masae, M. Norio, Tetsu to hagane, J. Iron and Steel Inst. Jap. 74(9), 1854-1861 (1989)

26. P.E. Irving, A. Kurzfeld, Metal Sci. 12(11), 495-502 (1978)

27. V.I. Vitvitskiy, M.O. Levitsky, Duryashin, Physical chemistry of mechanical materials 17(3), 107-108 (1981)

28. I.A. Nironovich, Physical chemistry of mechanical materials 18, 5, 22-25 (1980)

29. V.S. Sinyavsky, V.D. Valkov, V.M. Budov, Corrosion and protection of aluminium alloys, 368 (Metallurgy, Moscow, 1986)

30. A.N. Romanov, Physical chemistry of mechanical materials 16(2), 27-30 (1980) 